\title{
Discurso de Posse. Homenagem prestada, em nome da Congregação, pelo Professor José Ignácio Botelho de Mesquita
}

Excelentíssimo Senhor Professor Dalmo de Abreu Dallari, novo Diretor da Faculdade de Direito da Universidade de São Paulo, da velha Academia do Largo de São Francisco. Em 1974, tomou posse Vossa Excelência do cargo de Professor Titular de Teoria Geral do Estado nesta Faculdade. Contava então Vossa Excelência 42 anos. Quarenta e dois anos de uma vida árdua, que lhe impôs um duro aprendizado antes de o consagrar como professor. É no livro da vida que aprendemos o que devemos ensinar. Boa parte desse aprendizado foi feita aqui, nesta Faculdade. Primeiro como aluno do curso de bacharelado, a partir de 1953. Depois, entre 1960 e 1963, como aluno dos cursos de pós-graduação. Por fim, entre 1963 e 1974, como livre-docente. Em 1974 Vossa Excelência havia dedicado a metade de sua vida a aprender nesta Faculdade o que há de fundamental para a formação do jurista e do professor de Direito.

Expressou-o bem o compromisso que Vossa Excelência assumiu para consigo mesmo, ao tomar posse do cargo de Professor Titular. Disse então:

"Nesta oportunidade, que marca o início de nova etapa de minha existência, assumo também um compromisso: o de respeitar as tradições desta Casa, agindo coerentemente com elas, fazendo por transmití-las mais enriquecidas aos que me sucederem.

Vejo essas tradiçōes - acrescentou Vossa Excelência - numa tríplice perspectiva: a tradiçāo de vanguarda jurídica; a tradiçāo de cultura humanística; e a tradição de lutas em defesa dos valores fundamentais da pessoa humana"

Iniciou-se assim, meu caro professor e amigo, Dalmo de Abreu Dallari, iniciou-se assim o caminho que o elevaria, mais cedo ou mais tarde, mas inexoravelmente, pela força insuperável de sua comunhão com os ideais desta Faculdade, à condição de seu Diretor.

Convém relembrar que em 1974 nāo era fácil assumir aquele compromisso. E mais difícil ainda que assumí-lo, era dar-lhe o desejado cumprimento. Às 
nossas tradiçōes, opunha-se a vigência do Ato Institucional no 5 , expressão do autoritarismo que já nos vitimara antes, em 1932 e em 1937. Em 1932, sufocando a Revolução Constitucionalista e em 1937 golpeando a Constituição de 1934. Era impensável em 1974, que pudesse Vossa Excelência ser então Diretor desta Faculdade.

Quem quer, porém, que se detenha para contemplar a nossa história, a história da Academia, sabe que os regimes autoritários passam e ela permanece. Ela é constante nos seus ideais e no seu ensinamento. A constância é a qualidade daquilo que é impermeável ao tempo e aos tempos. É por isso que se pode falar aquí em tradição. Tradição é isto: é a constância no culto a valores que se creêm fundamentais e que só ganha corpo e força na medida em que sobreviva, esse culto, às investidas de seus adversários.

Assumir o compromisso de respeitar uma tradição destas, é prometer assumir riscos, assumir sacrificios, morder vezes sem contar o pó da derrota, é prometer levantar-se outra vez, contando como único ponto de apoio com a impossibilidade congênita, visceral, de agir de outro modo.

Os seus títulos, senhor professor, e a sua obra de jurista, são marcos fincados ao longo de sua trajetória, que atestam a fidelidade ao compromisso solenemente assumido. Assim são os títulos de Vice-Presidente da Associação Internacional de Juristas Democratas, de Presidente da Associação Brasileira de Juristas Democratas, de Presidente da Comissāo Pontifíca de Justiça e Paz, de membro honorário da Associação dos Advogados de São Paulo. E assim também seus livros: O Renascer do Direito, Constituição e Constituinte, Que sāo Direitos da Pessoa, Que é Participação Política, Vier em Sociedade.

São títulos e obras que espelham exatamente aquela tríplice perspectiva das tradições da Academia: a vanguarda do direito, o humanismo e a defesa intrasigente dos valores fundamentais da pessoa humana.

Essa conformidade com as tradições desta Academia constitue uma garantia perene de sobrevivência a qualquer regime autoritário. É esta a grande lição, que a Faculdade nos ensina.

E não é difícil entendê-la. Todo regime autoritário repousa sempre sobre uma mentira: a de que prosperidade material do povo e segurança do estado sāo mais importantes que os direitos fundamentais da pessoa humana. Essa mentira, como todas as demais, não resiste ao confronto com a verdade. No caso, com a verdade elementar de que, onde esses direitos não sejam respeitados, só haverá prosperidade e segurança para alguns, a custa do empobrecimento e da insegurança de todos os demais. Em contacto com a verdade, a autodestruição dos regimes autoritários é uma questão de tempo. Daí a necessidade sempre sentida por todos os governos autoritários com que já lidamos, de silenciar as tradiçōes 
desta Casa. $O$ fato é, porém, que nunca o conseguiram, ou nunca o conseguirão de todo. E o resultado é que os regimes autoritários se corrompem e passam, enquanto que as nossas tradições se fortalecem e ficam.

Por isso, se em 1974 era impensável que se tornasse Vossa Excelência, então, Diretor desta Faculdade, era de outro lado perfeitamente previsível que, guardando as tradições da Faculdade, certamente viria a ser seu Diretor no futuro. E o futuro, é hoje.

Saboreie esta vitória, Dalmo de Abreu Dallari. Ela é sua, como é também de todos aqueles que ousaram não calar.

Como sempre, porém, ao vencedor, os amigos recomendam cautela.

A sua vitória representa um grande passo na perspectiva da sua existência, é bem verdade, mas um passo muito pequeno na perspectiva da história de nossas instituiçōes. Não fica menor por isso, mas também não nos dispensa do cuidado de considerar as suas verdadeiras dimensões em face dos dias presentes e dos dias que nos aguardam no futuro próximo.

Vista nesta perspectiva, essa vitória não significa ainda que o autoritarismo tenha enfim sucumbido à própria mentira. Significa apenas que se acha momentaneamente enfraquecido. Malgrado meu, não vejo nos horizontes da Pátria nenhum sinal de que os maus tempos tenham ido embora. No centro dos ciclones - dizem os entendidos - no olho do furacão, não há vento, reina sempre uma silenciosa calmaria. É nesse momento, que os mais avisados restauram suas forças, recompõem seu abrigo e se aprestam para enfrentar o resto da tempestade.

Não é a primeira vez na nossa história que um regime autoritário, pressionado pelo sentimento de liberdade do povo, nos promete uma nova Constituiçäo. Esmagada a Revolução Constitucionalista de 1932, não tardou Getúlio Vargas em estender-nos o ramo de oliveira, convocando eleições para a Assembléia Nacional Constituinte, que se reuniu em 15 de novembro de 1933. Derrotada no Congresso a emenda Dante de Oliveira, depositária do clamor nacional pelo direito elementar de voto, não tardou o sistema em nos conceder a possibilidade da convocação de outra Assembléia Nacional Constituinte, como recompensa pela submissão ultrajante ao Colégio Eleitoral e às demais instituições criadas pelo movimento de março de 1964.

Também não é a primeira vez na nossa história que uma Assembléia Constituinte é convocada pelo Chefe de um governo autoritário e se reune sob um regime de exceçāo. Em 1933, como Chefe do Governo Provisório instituído por decreto de 11 de novembro de 1930, governava Getúlo Vargas com plenos 
poderes, tanto executivos como legislativos. Em 1986, o País é governado por decretos-leis pelo Presidente da República que, mercê do nosso regime constitucional, continua sendo, não só o Comandante Supremo das Fôrças Armadas, mas também o representante institucional do movimento de março de $\left.1964 .{ }^{*}\right)$

Também não é a primeira vez na nossa história que uma Assembléia Nacional Constituinte se reúne em meio de um profundo enfraquecimento de todas as forças políticas em atividade no País. Em 1933, o constitucionalismo-liberal radicado em São Paulo ainda não conseguira reerguer-se da derrota que o vitimara; e o reformismo nacionalista e autoritário do tenentismo se achava eclipsado por um novo ativismo político, representado, na Europa, pelo facismo e, aqui, pelo Integralismo. No vazio criado à sua volta, organizou-se, a partir de uma facção do Partido Comunista, a Aliança Nacional Libertadora (ALN); e a esquerda começou a tomar corpo, reunindo elementos progressitas da classe média aos sindicatos trabalhistas militantes para apoiar um movimento radical. Em 1986, os grandes partidos de situação e de oposição se encontram destruídos pelos acordos a que chegaram para a eleição de Tancredo Neves e José Sarney pelo Colégio Eleitoral, que pouco antes era denominado de "espúrio". As forças que, em São Paulo, deram sustentação à eleição de Franco Montoro e ao movimento pela "Diretas Já", se desacreditaram ao ponto de permitirem a eleição de Jânio Quadros para Prefeito da Capital. Nesse vazio, esquerda e direita voltam a tender para a radicalização. Criam-se entidades não partidárias, cujas metas se assentam iniludivelmente na disposição de sobrepor o próprio poder a quaisquer considerações de ordem jurídica. Alimenta essa radicalismo, por igual, tanto a desilusāo causada pela ida ao Colégio Eleitoral e a subsequente redução da Constituinte autônoma à Constituinte congressual, como, de outro lado, o desastre econômico e moral em que desembocou o regime militar. Diante desse quadro, o organismo estatal tende naturalmente a enrijecer-se, a fazer-se paternalista e mais autoritário.

Há índicios claros, por isso, de que a Constituição a ser votada em 1987, se o for, correrá o risco de repetir o destino da Constituição de 1934. As tendências políticas em ascenção na Europa e nos Estados Unidos, fortemente conservadoras, conforme se vê na política de Reagan, de Tatcher, e no declínio de Miterand, projetam numa imagem de fortalecimento dos movimentos orientados para a direita. Compóem, no plano internacional, o pano de fundo que, em 1937, autorizou Getúlio Vargas a dirigir-se à Naçāo dizendo não haver para nós outra alternativa senão "um regime forte, de paz, justiça e trabalho para reajustar o organismo político às necessidades econômicas do país".

(*) cf. nosso artigo in Visão 16.10.85, n 41, págs.22/23 
Quem de nós, senhor Diretor, não se tem cansado de ouvir nos dias de hoje essas mesmas palavras, ditas e reditas como se fossem algo mais que um disfarce para submeter a ordem jurídica a interesses particulares?

Quem de nós não está ouvindo hoje essas mesmas palavras dita por todos os que se colocam tanto à esquerda como à direita da ordem democrática?

Quanto de nós, porém, ainda são incapazes de ver nestas palavras uma pérfida, velha e solene mentira!

Eis aí, senhor Diretor, o que nos mostra a história de nosso país, de que sempre foi parte a história desta Faculdade. Ela nos mostra que vivemos um momento, talvez breve, de retração das tendências autoritárias. A democracia ainda está longe.

Neste momento não podemos nos esquecer do passado, sob pena de voltarmos repetí-lo. É hora de nos concentrarmos em torno dos valores fundamentais da ordem jurídica e dar combate decidio a todas as tendências que, em nome da justiça, da paz, do trabalho, da segurança e da prosperidade econômica, ignoram solenemente e menosprezam as instituiçōes jurídicas; que não vêem nas leis mais que a solução de sua necessidades particulares, em desacordo com as necessidades de todos.

É hora de fortalecermos a Faculdade, unindo os seus professores, os seus alunos e os seus funcionários em torno da consciência dos imperativos que este momento nos impõe.

Temos que estar organizados e confiantes de nós mesmos. Temos que ser competentes e responsáves. Temos que ser eficientes. Temos que ser leais à nossa missão histórica de formar e aperfeiçoar a consciência jurídica da nação. Temos que resistir à tentação da popularidade imediata e trabalhar por uma respeitabilidade permanente diante dos olhos de nosso povo. Temos que ser grandes para que, no momento em que se faça necessário, possamos ser vistos em meio da tempestade e possa, a nossa voz, ser ouvida acima do ulular dos ventos.

É solene este momento, Senhor Diretor, e grave, como o que antecedia nos templos da antiguidade a oferenda dos sacrifícios.

Está porém à altura de suas forças, de sua capacidade, de sua inteligência e de sua comprovada generosidade. 
Em nome da E. Congregação e no meu próprio, desejo a Vossa Excelência que o seu trabalho seja coroado de êxito, para o seu bem e felicidade de todos nós.

Discurso proferido na Faculdade de Direito, em 11.08.1986. 